\title{
Experimental and Simulative Study on the Hydrodynamics of the Rectangular Otter Board
}

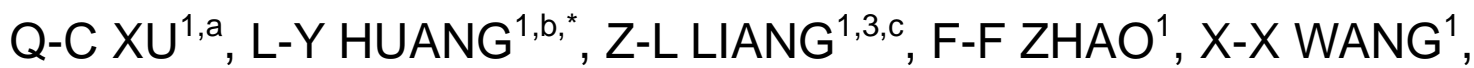 \\ $\mathrm{R}_{\text {WAN }}{ }^{1,2}, \mathrm{Y}-\mathrm{L}_{\text {TANG }}{ }^{1}, \mathrm{~T}-\mathrm{W} \mathrm{DONG}^{4}, \mathrm{H} \mathrm{CHENG}^{1}, \mathrm{~J}^{1} \mathrm{Q} X \mathrm{XU}^{1}$ \\ ${ }^{1}$ College of Fishery, Ocean University of China, Qingdao 266003, China
}

\begin{abstract}
${ }^{2}$ Function Laboratory for Marine Fisheries Science and Food Production Process, Qingdao National Laboratory for Marine Science and Technology, Qingdao 266071, China

${ }^{3}$ College of Ocean, Shandong University (Weihai), Weihai 264209, China

${ }^{4}$ Shandong Hrdrobios Resources Conservation and Management Center, Yantai, 264003, China

axuqcouc@163.com, bhuangly@ouc.edu.cn, 'Liang@ouc.edu.cn

${ }^{*}$ Corresponding author
\end{abstract}

Keywords: Rectangular Otter Board, Numerical Simulation, Hydrodynamic Performance.

\begin{abstract}
The otter board is a vital component of single trawl system, of which the hydrodynamics can directly affect the trawl operation and catch performance. This paper studied the hydrodynamics of the rectangular otter board using numerical simulation, and the simulation accuracy was verified by flume tank experiment. In addition, the effect of different water layers on the hydrodynamics of the otter board is also studied. Experiment results show that the rectangular otter board has the maximum lift coefficient 1.070 with the flow angle attack at $40^{\circ}$. Simulation results have the similar tendency with experiment results, the simulation results of maximum lift coefficient is 1.227 $\left(\alpha=40^{\circ}\right)$, which is similar to the experiment results, and the flow angle is the same as experiment results. Simulation study of different water layers show that the maximum lift coefficient and the critical angle in the free stream is bigger than that of in the bottom. The results can provide basis for the angle setting of the otter board while operating.
\end{abstract}

\section{Introduction}

Single trawling is one of the main fishing modes widely used in fisheries for its activeness, flexibility and efficiency. The otter board, which is directly related to the horizontal expansion of fishing net and consequently affects the fishing efficiency, and economic effectiveness of the single trawl, is a vital component for the single trawl system. According to the previous study, the resistance of the otter board accounts for up to $30 \%$ of the total-system drag, which is ranked second, just less than the wing-net resistance ${ }^{[1]}$. Therefore, research on the hydrodynamic performance of the otter boards has great significance for energy saving in fishery and extensive investigations about the hydrodynamics of the otter board have been carried out during the past decades $^{[2-4]}$.

Generally, the model tests and sea-trials were two main measures to study the hydrodynamic characteristics of the otter board for many years. However, these methods are time-consuming and costly. Computational fluid dynamics (CFD), a numerical method for solving the equation of fluid mechanics, has been developed rapidly with the progress of computer technology. Having the advantages of low cost and being able to simulate more complex situations, it has been widely used in the development and designation of ships and artificial reefs ${ }^{[5,6]}$. And now, researchers begin to study the hydrodynamic properties of otter boards using numerical simulation ${ }^{[7,8]}$.

The otter board has many types (i.e. rectangular otter board, V-type otter board, etc.), among which the rectangular otter board is widely used in the shrimp trawl. The hydrodynamics of the rectangular otter board is studied in the present work by flume model experiment and numerical simulation. In addition, the effect of different streams on the hydrodynamics of the otter board is also simulated. The results can provide basic data for the productive practice of the otter board. 


\section{Materials and Methods}

\section{Flume Tank Experiment}

The prototype otter board for the experiment is a rectangular otter board which is used in small single trawl, with a power of $15 \mathrm{~kW}$ and working at $2 \mathrm{kn}$. The otter board is made of iron and wood, and its main dimensions are given as follows: the wing span $l_{1}=0.4 \mathrm{~m}$, the chord $c_{1}=1.0 \mathrm{~m}$ and the aspect ratio $\lambda=0.4$. The model otter board is designed based on the Froude's law and its main dimensions are: $l_{2}=0.2 \mathrm{~m}, c_{2}=0.5 \mathrm{~m}, \lambda=0.4$. The conversion equation is given as follows:

$$
\frac{l_{1}}{l_{2}}=s, \frac{S_{1}}{S_{2}}=s^{2}, \frac{u_{1}}{u_{2}}=\sqrt{s}
$$

Where $l$ is the wing span, $S$ is the plane area, $u$ is the flow velocity and $s$ is the scale ratio. The subscript ' 1 ' represents the prototype while the subscript ' 2 ' stands for the model. The scale ratio used in the present work is set to $s=2$ according to the size of the flume tank.

Model tests were performed in a circulating tank at the Ocean University of China (test section: length $4.0 \mathrm{~m}$, width $1.2 \mathrm{~m}$, and water depth $1.0 \mathrm{~m}$ ) from Mar $28^{\text {th }}$ to $A p r 5^{\text {th }}$ in 2015 . The flume tank is equipped with Vectrino current meters (range: 0 2 m/s, accuracy: $\pm 0.5 \%$ ) and a force sensor of six-component (range: 0 50 kg, accuracy: 0.3\%).

The otter board is fixed to the bottom of the six-component force sensor through supporting rods. The whole system can be rotated to form an angle of attack (AOA) relative to the direction of the flow. During the experiment, the otter board is located at a distance of $1.5 \mathrm{~m}$ from the flow entrance of the flume and a depth $0.15 \mathrm{~m}$ beneath the water surface. The layout of the model test is shown in Fig.1.

During the experiment, the flow velocities of tests varies from $0.3 \mathrm{~m} / \mathrm{s}$ to $0.7 \mathrm{~m} / \mathrm{s}$ (at an increment of $0.1 \mathrm{~m} / \mathrm{s}$ ) and the angles of attack (AOA, $\alpha$ ) is changed in the range of $10^{\circ} \sim 50^{\circ}$ (with a step of $10^{\circ}$ ). In addition, the flow velocity is measured at six points, which are all positioned on the center plane of the tank with a depth of $0.15 \mathrm{~m}$ for the odd-numbered stations and $0.35 \mathrm{~m}$ for the even-numbered ones. The horizontal interval between stations is $0.50 \mathrm{~m}$ with the front two stations (No.1 and 2) located at a distance of $2.0 \mathrm{~m}$ from the entrance. And the obtained data is processed according to the following equations:

$$
\begin{aligned}
& C_{L}=\frac{F_{L}}{\frac{1}{2} \rho S u^{2}} \\
& C_{D}=\frac{F_{D}}{\frac{1}{2} \rho S u^{2}} \\
& R_{e}=\frac{u c}{v}
\end{aligned}
$$

Where $F_{L}$ and $F_{D}$, i.e. the force component perpendicular or parallel to the income flow, are the measured lift and drag forces respectively, $\rho$ is the fluid density, $S$ is the plane area of the otter board, $u$ is the actual velocity of incoming flow, $R_{e}$ is the Reynolds number, $c$ is the chord of the otter board and $v$ is the kinematic viscosity of fluid. 


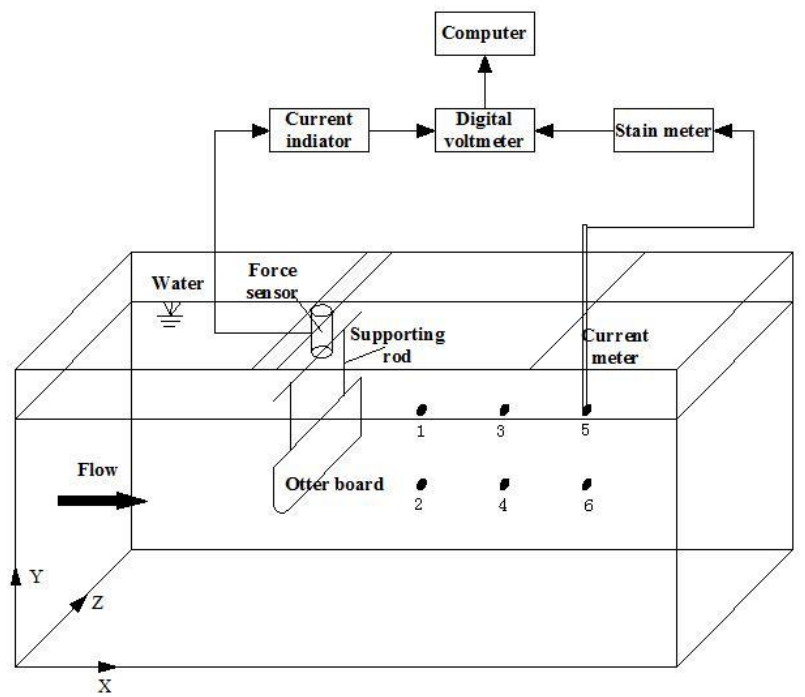

Fig. 1 The Layout of the Otter Board

\section{Numerical Simulation}

The numerical simulation is carried out by CFX analysis (realizable $k \sim \varepsilon$ model) contained in the software ANSYS 15.0. To make it consistent with the flume model test, the testing section of the tank is taken as the calculation domain $(4 \mathrm{~m} \times 1.2 \mathrm{~m} \times 1 \mathrm{~m})$ and the otter board is located at the same position as in the flume tank experiment. The computational domain and boundary conditions are shown in Fig.2.

The fluid is assumed to be incompressible. The velocity at the inlet boundary is assumed to be a uniform flow in the $x$-direction while the relative pressure is set to $0 \mathrm{~Pa}$ at the outlet boundary. The turbulence is set to 5\% and the otter board is assumed to be no-slip wall. The other boundaries are no-slip wall by default. The total number of meshes and nodes are approximately $1.64 \times 10^{6}$ and $4.25 \times 10^{5}$ respectively. The grids around the otter board are intensified by controlling the facing size.

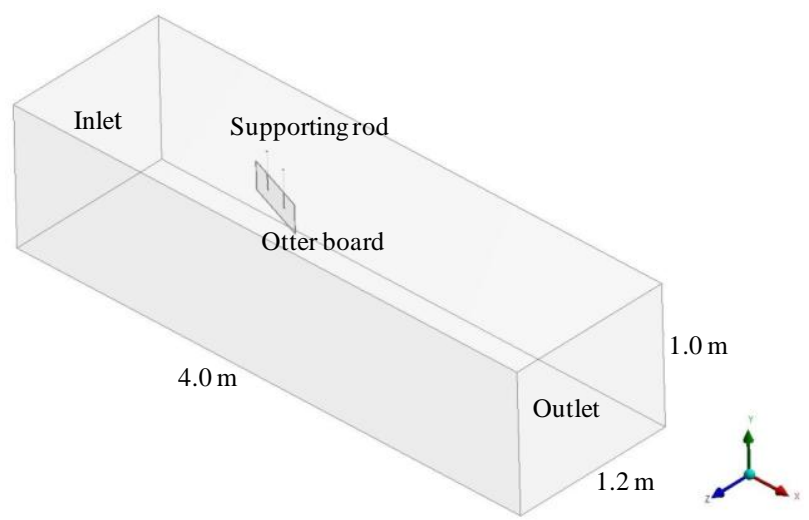

Fig.2 Calculation Domain and Boundary Conditions

\section{Results}

Based on the experiment data, the drag, lift coefficient is calculated according to Eq. 2 \& Eq. 3 and the Reynolds number is calculated by Eq.4. The relationship between lift, drag coefficients and Reynolds number of rectangular otter board for each angle of attack are presented in Fig.3. The drag coefficient decreased slightly with an increase in the Reynolds number at an angle attack of $10^{\circ}$ and $20^{\circ}$, the lift coefficient decreased slightly with the increase of Reynolds number at an angle of attack of $30^{\circ}$. For the other angles of attack, the hydrodynamic coefficient shows almost constant values with the increase of Reynolds number. Therefore, the self-modeling region of Reynolds 
number for the otter board is $1.32 \times 10^{5} \sim 3.07 \times 10^{5}$, and the values used in the subsequent analyses were in the average value at every angle of attack in the experiment flow velocity range.
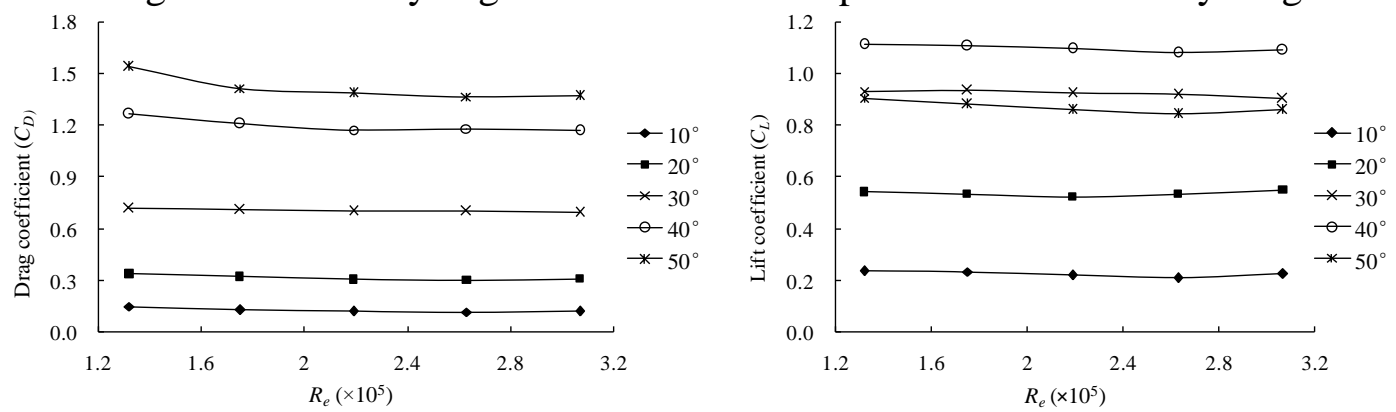

Fig.3 Relationship between Lift, Drag Coefficients and Reynolds Number of Model Otter Board for Each Angle of Attack

\section{The Hydrodynamic Forces}

Presented in Table 1 is the lift/drag force acting on the otter board at a velocity of $0.6 \mathrm{~m} / \mathrm{s}$. The data shows that the simulation results of CFX are close to the experiment results. For the drag force value, the CFX simulation has a relative deviation of $-14.3 \% \sim 1.9 \%$ comparing with the experiment data and the average relative deviation is $-10.29 \%$. For the value of lift force, the CFX simulation has a relative deviation of $12.8 \% \sim 20.6 \%$ with an average deviation of $16.6 \%$.

Tab.1 The Lift/Drag Forces at a Velocity of $0.6 \mathrm{~m} / \mathrm{s}$

\begin{tabular}{ccccccc}
\hline & AOA & $10^{\circ}$ & $20^{\circ}$ & $30^{\circ}$ & $40^{\circ}$ & $50^{\circ}$ \\
\hline \multirow{2}{*}{ Drag } & Experiment & 1.789 & 5.051 & 12.261 & 20.915 & 24.273 \\
force/N & CFX & 1.533 & 5.105 & 11.601 & 19.513 & 24.724 \\
& Deviation & -0.143 & 0.011 & -0.054 & -0.067 & 0.019 \\
\hline \multirow{2}{*}{ Lift } & Experiment & 3.506 & 9.354 & 16.281 & 19.206 & 15.907 \\
force/N & CFX & 4.037 & 11.284 & 18.357 & 22.056 & 19.022 \\
& Deviation & 0.151 & 0.206 & 0.128 & 0.148 & 0.196 \\
\hline
\end{tabular}

\section{Relationship between Hydrodynamic Coefficient and Angle of Attack}

The lift/drag coefficients $\left(C_{L}\right.$ and $\left.C_{D}\right)$ against the angle of attack are plotted in Fig. 4 , which is the average value of hydrodynamic coefficients in the self-modeling region of Reynolds number. It shows the drag coefficient decreases with the increasing of angle of attack, while the lift coefficient increases first and then decreases. And the maximum lift coefficient $\left(C_{L-M A X}\right)$ is 1.070 at an angle of attack of $40^{\circ}$. The simulation results have a similar tendency with the experiment results for both drag coefficient and lift coefficient. And the simulated $C_{L-M A X}$ is 1.227 , which is slightly higher than the experiment value but the angle of attack is almost the same as the experiment result.
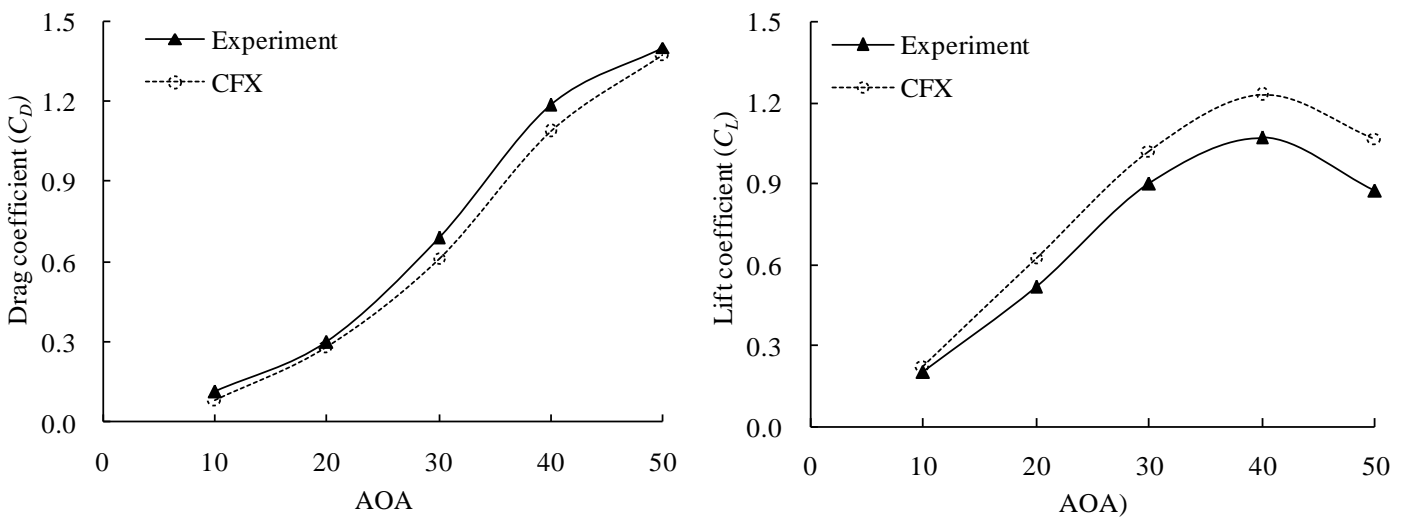

Fig.4 The Relationship between Drag, Lift Coefficients and Angle of Attack 


\section{The Lift-drag Ratio of the Otter Board}

The lift-drag ratio is ratio of lift coefficient to drag coefficient, which represents the efficiency of the otter board and is a main parameter for the performance of the otter board. The relationship between lift-drag ratio and angle of attack is shown in Fig.5.The experiment data shows that the lift-drag ratio decreases with the increasing of the angle of attack, and maintains a high value (higher than 1.5) while the angle of attack in the range of $10^{\circ} \sim 25^{\circ}$. The CFX simulation for lift-drag ratio has a similar tendency with the experiment results, and it is a little higher.

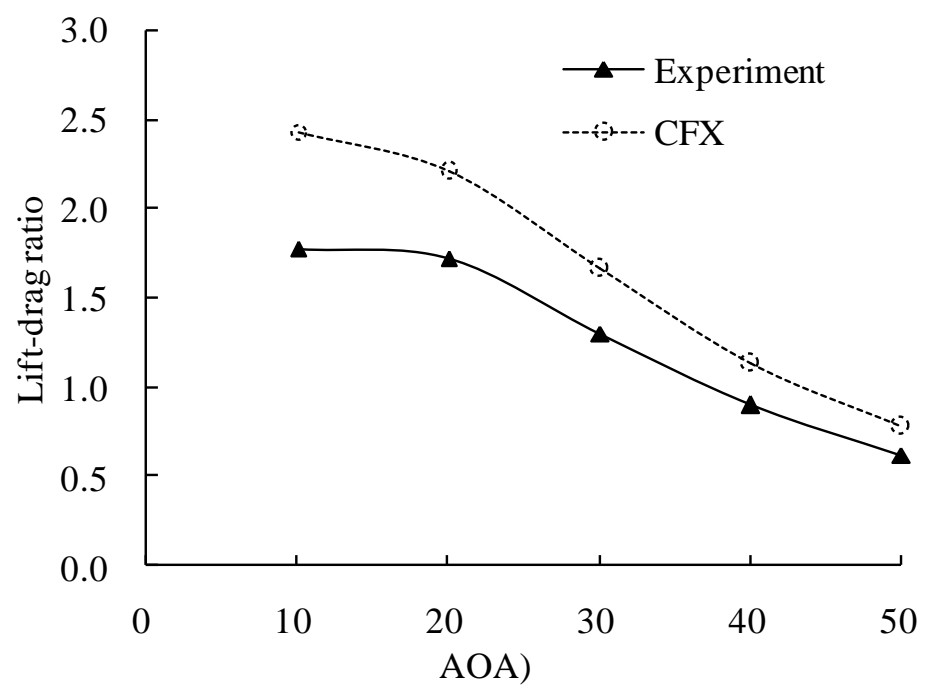

Fig.5 The Relationship between Lift-drag Ratio and Angle of Attack

\section{Simulation Results of Fluid Velocity}

The data of fluid velocity, measured or simulated at station No.1 and 5, is presented in Table 2 as the velocity of incoming flow $v=0.3 \mathrm{~m} / \mathrm{s}$ for No. 1 and $v=0.4 \mathrm{~m} / \mathrm{s}$ for No.5. Results show that the simulated velocity data shows good agreement with the experiment one. The range of relative deviation is $-5.7 \% \sim 8.5 \%$ with the average value at $3.1 \%$. Generally, the CFX model can be used to simulate the flow distribution around the otter board.

Tab. 2 The Velocity Data at Station No. $1(v=0.3 \mathrm{~m} / \mathrm{s})$ and No. $5(v=0.4 \mathrm{~m} / \mathrm{s})$

\begin{tabular}{ccccccc}
\hline & AOA & $10^{\circ}$ & $20^{\circ}$ & $30^{\circ}$ & $40^{\circ}$ & $50^{\circ}$ \\
\hline 1-point & Experiment & 0.297 & 0.290 & 0.276 & 0.253 & 0.211 \\
velocity & CFX & 0.296 & 0.273 & 0.268 & 0.264 & 0.229 \\
$(0.3 \mathrm{~m} / \mathrm{s})$ & Deviation & -0.001 & -0.057 & -0.030 & 0.044 & 0.085 \\
\hline 5 -point & Exoeriment & 0.408 & 0.402 & 0.409 & 0.407 & 0.410 \\
velocity & CFX & 0.404 & 0.393 & 0.394 & 0.406 & 0.403 \\
$(0.4 \mathrm{~m} / \mathrm{s})$ & Deviation & -0.011 & -0.022 & -0.037 & -0.002 & -0.016 \\
\hline
\end{tabular}

\section{Effect of Water Layers}

In view of the above data, the results of numerical simulation show good agreement with those of flume tank experiment; therefore, the effect of different water layers on the hydrodynamics of the otter board is studied using numerical simulation. The otter board is set to the bottom and the free stream of the water in the present study, and the results are plotted in Fig. 6. It shows that the water layer has a slight effect on the drag coefficient and affects the lift coefficient greatly. While the otter board is in the free stream, the $C_{L-M A X}$ is 1.227 at an angle of attack of $40^{\circ}$, which is bigger than that of in the bottom $\left(C_{L-M A X}=1.108,30^{\circ}\right)$. And the value of $C_{L-M A X}$ in the bottom reduced by $10 \%$ compared with that of in the free stream. 

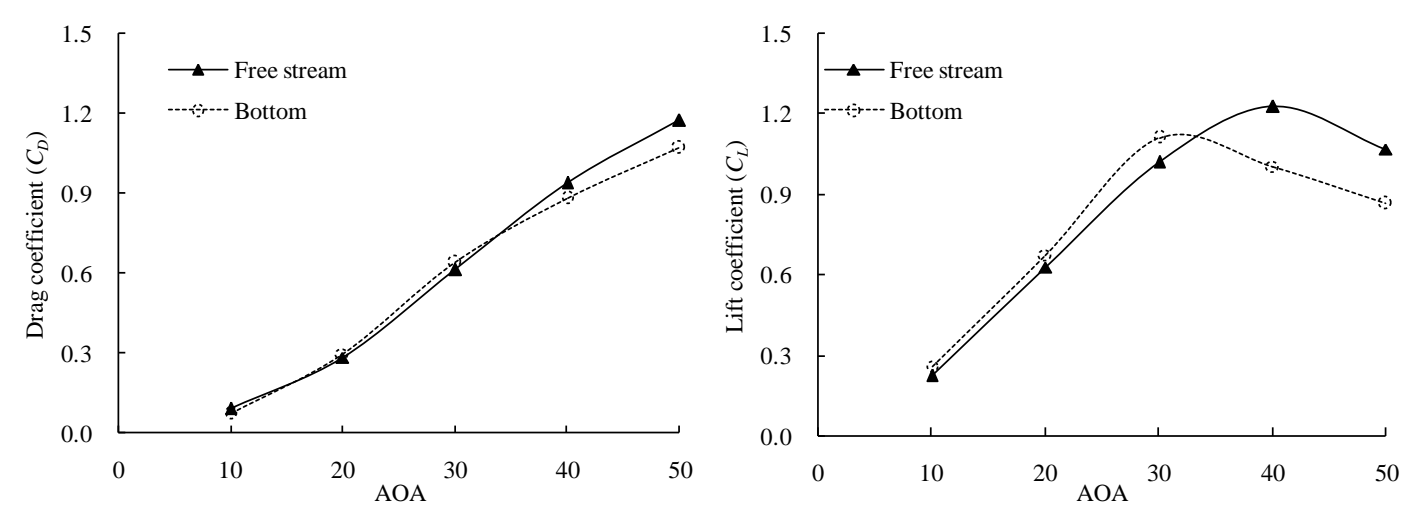

Fig.6 The Lift, Drag Coefficients of the Otter Board in Free Stream or Bottom

\section{Discussion}

The flume tank experiment obtained that the self-modeling region of Reynolds number for the model otter board is $1.32 \times 10^{5} \sim 3.07 \times 10^{5}$, which shows that the hydrodynamics of the model otter board is agreement with that of the prototype otter board according to the research of Chen ${ }^{[9]}$.The experiment results show that the $C_{L-M A X}$ of this otter board is 1.070 , which is less than that of the V type otter board $\left(C_{L-M A X}=1.31\right.$ [2]) and vertical cambered V type otter board $\left(C_{L-M A X}=1.509\right.$ [4]). Hence, it has a poorer hydrodynamic performance, while it has the advantages of simple structure, good stability and low cost, it is widely used in the single trawl along china's costal sea. Consequently, the optimization of the parameters for this otter board is needed in the further study.

The validation of the numerical simulation shows that the simulation results good agreement with the experiment results both in the hydrodynamics and the velocity. In addition, the effect of different water layers shows that the otter board has a better performance when it is in the free stream, which is agreement with the research of Park ${ }^{[10]}$. Therefore, the CFX simulate model can be used to study the hydrodynamic of the otter board and the flow distribution around the otter board.

\section{Acknowledgement}

The authors thank staffs of the Laboratory of Fishery Engineering for their technical help. The present work is supported by Special Fund for Agro-scientific Research in the Public Interest (201203018; 201303050-02; 31072246).

\section{References}

[1] Sterling, D. The physical performance of prawn trawling otter boards and low opening systems AME CRC Report, Project 1.4.4. Sterling Trawl Gear Service, Brisbane, (2000)204 pp.

[2] ZHANG Xun, WANG Jin-hao, WANG Ming-yan. Hydrodynamic characteristics of rectangular cambered V type otter board-one: Relationship between cambered ratio of fairwater fin and hydrodynamic characteristics of otter board. Journal of Fishery Science of China, (2004), 11 (z1):5-8.

[3] ZHUANG Xin, XING Bin-bin, XU Chuan-cai et al. A review of flowing visualization of different types of otter board. Journal of Dalian Fisheries University, (2015), (2):237-242.

[4] LIU Jian, HUANG Hongliang, WU Yue et al. Model test of hydrodynamic characteristics of two types of vertical cambered slotted boards. South China Fisheries Science, (2015), (1): 68-74.

[5] Percival S, Hendrix D, Noblesse F. Hydrodynamic optimization of ship hull forms. Applied Ocean Research, 2001, 23(6): 337-355.

[6] JIANG Zhaoyang, LIANG Zhenlin, TANG Yanli, et al. Numerical simulation and experimental 
study of the hydrodynamics of a modeled reef located within a current. Chinese Journal of Oceanology and Limnology, 2010, 2 (2): 267-273.

[7] LI Chong-cong. Preliminary study on the hydrodynamic performance and numerical simulation of a V-shaped otter board [D]. Ocean University of China, Qingdao. (2012)

[8] Takahashi Y, Fujimori Y, Hu F, et al. Design of trawl otter boards using computational fluid dynamics. Fisheries Research, 2015, 161:400-407.

[9] CHEN Xuezhong. The theory and method of model test of fishing gears [M]. ShangHai Scientific \& Technical Publishes, 2011, 80-82, 396-401.

[10] Park C, Matuda K,et al. The Effect of the Bottom on the Hydrodynamic Characteristics of the Flat Plates. Nippon Suisan Gakkaishi, 1993, 59(1): 79-84. 